\title{
REPORT OF COMMISSION APPOINTED TO FURTHER THE STUDY OF SOLAR AND TERRESTRIAL RELATIONSHIPS
}

The Commission was appointed provisionally by the Executive Committee of the International Research Council in June, I924, and originally consisted of C. G. Abbot, S. Chapman (Chairman), H. Deslandres, G. Ferrie, C. E. St John, G. C. Simpson, C. Störmer. The Commission was given power to add to its number.

In October, I924, C. Chree, then President of the Section of Terrestrial Magnetism of the International Union for Geodesy and Geophysics was added to the Commission at the request of the Section.

The Commission presented a first report to the International Research Council in July, I925, when the nomination of the Commission by the Executive Committee was confirmed. The Commission was reappointed for three years, with the addition of $\mathrm{G}$. Abetti.

\section{SECOND REPORT TO THE INTERNATIONAL RESEARCH COUNCIL}

\section{(I) Publication of the First Report}

The Commission provisionally appointed by the Executive Committee of the Council in June, I924, presented its first report to the International Research Council in July, I925. This report, which reviewed the state of knowledge of solar and terrestrial relationships at the time, also made various recommendations with a view to extending that knowledge. Together with

(i) a number of memoranda by various authors on different branches of science coming within the scope of the Commission's work, and

(ii) a summary and bibliography of recent papers on solar relationships with meteorology, prepared by Dr C. E. P. Brooks in continuation of the bibliography by Drs Helland-Hansen and Nansen,

the first Report was published in book form in I926, by means of a grant made to the Commission for this purpose by the Executive Committee of the Council. Seven hundred and fifty copies of the Report were printed, and the majority of these were distributed to scientific libraries, institutions, and individual investigators; the distribution was made in co-operation with, and partly by, the Secretaries of the International Unions of Astronomy, Geodesy and Geophysics, and Radio-telegraphy. A few copies of the first Report are still on hand.

(2) Regulations for the Constitution of the Commission

When, in July, r925, the Council confirmed the Commission as provisionally nominated, and reappointed it for three years (with the same personnel as before save for the addition of Dr G. Abetti), the Commission was directed to prepare, "in collaboration with those interested in the field", "regulations for a suitable form of standing organization" to fulfil the duties for which the Commission was constituted. In accordance with this request the Executive Committees of the International Unions for Astronomy and for Radio-telegraphy, and the Sections of Terrestrial Magnetism and Electricity, and of Meteorology, 
of the International Union for Geodesy and Geophysics, were consulted in the matter. The replies received appeared to indicate a desire that the Commission should be continued, and that the various International Unions concerned should be consulted regarding the membership of the Commission.

In consequence the Commission propose that, if the International Research Council sees fit to continue the Commission:

(i) Each of the following bodies be invited to name representatives, to the number stated, for appointment to the Commission by the Council:

(a) The International Union for Astronomy: two representatives.

(b) The International Union for Radio-telegraphy: one representative.

(c) The Section of Terrestrial Magnetism and Electricity of the International Union for Geodesy and Geophysics: one representative.

(d) The Section of Meteorology of the International Union for Geodesy and Geophysics: one representative.

(ii) The Commission should consist of persons so appointed, together with others whom, from a survey of the whole field, the Council deem it desirable to appoint: the total membership of the Commission should, however, not exceed twelve.

(iii) The Council should appoint the Commission for a period of three years at a time, reviewing and if necessary revising its composition at the end of each such period.

(iv) The Commission should have power to add to their number during their period of appointment, subject, however, to the specified total number not being exceeded.

(v) The Chairman of the Commission should be appointed by the Council.

The Commission regard it as desirable that the Chairman should not hold office for more than two successive three-year periods.

If the above proposals are accepted by the Council, the Commission recommend that, as a transitional measure, its present period of appointment be extended to December 3I, I928, to enable the above bodies to be consulted. Succeeding Commissions could then be appointed for successive periods of three years from January I, I929, and be directed to present their final reports to the Council in or about the month of July of their last year of appointment, when also the Council could again consult the above bodies as to their representation on the succeeding Commission.

\section{(3) Action taken on the First Report}

(i) The recommendations made in the first Report mainly dealt with the need for further observations of various kinds and in different countries: particularly with the need for more magnetic and auroral observations at stations in or near the auroral zone, and for further measurements of the amount and distribution of solar radiation, and its absorption in the earth's atmosphere. These and similar recommendations were communicated through the General Secretary of the International Research Council to the Governments and national research organizations concerned: the time since elapsed has been too short for it to be possible to report any definite action as a result of these recommendations. Progress has, however, been made in some of the suggested directions, notably by the establishment of a magnetic observatory at Godhaven, Greenland, by the Government of Denmark; by the foundation of a magnetic and auroral 
institute at Tromsö, Norway, with the aid of the Rockefeller International Education Board; by the establishment of a new solar radiation observatory in South-West Africa by the Smithsonian Institution; and by the extension of the magnetic equipment of the Meanook Observatory in Canada. Discussion is proceeding in America as to the possibility of organizing auroral observations at Fairbanks, Alaska $\left(57^{\circ} 3^{\prime}\right.$ N., $135^{\circ} 20^{\prime}$ W.).

(ii) The Commission recommended that the International Union for Astronomy be asked to organize a scheme for the characterization of successive Greenwich days (from midnight to midnight) according to the state of the sun with respect to one or more of its variables. In conjunction with the magnetic character figures already internationally assigned, such solar character figures would greatly facilitate the study of solar relationships with terrestrial magnetism. This recommendation was considered by the International Union for Astronomy at its meeting at Cambridge in r925, and was referred to a Committee of the Union: the report of this Committee has been considered at the Leiden (r928) meeting of the Union, and a provisional scheme has been prepared*. It is proposed that a bulletin shall be issued bi-monthly or quarterly by the Observatoire Fédéral, Zurich, giving daily character figures for four separate solar phenomena. These have been chosen as being those most likely to show correlation with the terrestrial phenomena which appear to depend on solar emissions projected in limited streams. Hence the character figures will refer to the state of the sun (in these four different respects) within a limited central sector of the sun's disc.

(iii) The Commission recommended that Dr L. A. Bauer, then Secretary of the Section of Terrestrial Magnetism and Electricity of the International Union for Geodesy and Geophysics, be asked to formulate a scheme for a service to supply information to solar observatories as to magnetic storms, in progress or prospective (in accordance with the 27-day recurrence tendency). As a result of conferences which he held with Drs Hale, Adams and Nicholson of the Mount Wilson Solar Observatory, it was decided first to make trial investigations there, and a horizontal force magnetograph had been installed for the purpose. The records will be compared in detail with solar phenomena, and it is hoped that in due course it will be possible to decide whether and in what manner current information as to magnetic phenomena can usefully be supplied to solar observatories.

\section{(4) Memoranda on Recent Progress}

Attached to the present Report there are numerous memoranda, contributed by members of the Commission and by other investigators at their request, which describe recent work on various aspects of solar and terrestrial relationships. While the Commission do not hold themselves collectively responsible for the opinions and conclusions expressed in these memoranda, which in some cases necessarily deal with controversial matters, they regard the memoranda as evidence of great and fruitful activity during the past few years in many subjects bearing on solar and terrestrial relationships. On account of the wide variety of these investigations, and the desirability that workers in these fields should have information as to work in cognate branches made readily accessible to them, the Commission recommend the publication and distribution of the Memoranda with this Report.

* See p. 235.

265 
(5) Recommendations

\section{Solar relationships with terrestrial magnetism}

(a) In regard to terrestrial magnetic observations the chief need continues to be that of further continuously-recording magnetic observatories in high magnetic latitudes. The Commission consider it desirable that new continuouslyrecording magnetic observatories be instituted at

(i) Jan Mayen or Spitzbergen.

(ii) North-eastern Canada.

(iii) Northern Alaska, additional to, and to the north of, the existing observatory at Sitka.

(iv) Northern Russia and Siberia.

(b) The Commission consider it desirable that the daily character figures for magnetic disturbance be supplemented by daily character figures relating to the amplitude of the portion of the daily magnetic variation which is of quiet-day type, as representing a separate phenomenon varying independently of the degree of magnetic disturbance.

\section{Solar relationships with aurorae}

(c) The Commission consider it desirable that regular auroral observations, preferably photographic, be made at as many points as possible around the auroral zone, and recommend the plan of observations outlined by the Committee appointed at Prague, by the Section of Terrestrial Magnetism and Electricity of the International Union of Geodesy and Geophysics, to prepare an atlas of auroral forms and a scheme of observations based thereon. Observatories such as are recommended under $(a)$ would be specially suitable for such observations.

The Commission note the advance recently made by McLennan and his associates in the definite identification of the green auroral line as due to atomic neutral oxygen, and anticipate considerable further accessions to our knowledge of the manner in which the upper atmosphere is affected by solar emanations as a result of further observations and laboratory study of the auroral spectrum.

\section{Solar relationships with meteorology}

(d) The Commission regard the regular detailed observation of

the amount and spectral distribution (i) of the total solar radiation, and

(ii) of the absorption in the earth's atmosphere, particularly by ozone, as of primary importance.

The Commission consider it desirable that regular observations of this kind should be made at observatories, preferably situated at a high altitude, in the following regions:
(i) Australia.
(ii) Europe.
(iii) India.
(iv) Indo-China.
(v) Japan.

(e) The Commission note the important step made by the institution of regular daily measurements of the intensity of the sun's ultra-violet radiation at Mount Wilson and Tucson Observatories, and consider it important that intensity figures 
for this radiation on each day be regularly published for comparison with magnetic and other data.

(f) The Commission note the important advances recently made in our knowledge of the ozone-content of the upper atmosphere variations, by Professors Fabry and Buisson and their fellow-workers in France, and by Dr Dobson and those who have co-operated in his scheme of systematic observations in England and many other parts of the world. They consider that the variations are of great interest from the standpoint of solar and terrestrial relationships, and that regular observations of the ozone-content of the atmosphere should continue to be made, and should be put on a permanent basis, by the adoption of these observations, including their reduction, as a part of their regular programme, by a number of existing observatories, well distributed over the world.

(g) The Commission note that the existence of a temperature of about $300^{\circ}$ absolute at about 50 kilometres height in the atmosphere, deduced by Lindemann and Dobson from their theory of meteors, has been confirmed in an independent way by the study of the propagation of sound to great distances, the sound-waves being refracted downwards in the warm upper layer; and also that Gowan, by the study of the absorption of solar radiation by the ozone known to exist in the upper atmosphere, has shown that such temperatures can be theoretically accounted for. The measurement of the time of propagation of sound to great distances, and the determination of the inclination of the down-coming waves, permit the estimation of the temperature of the atmosphere at a height inaccessible to direct observation. As the temperature at such heights is likely to be more directly controlled by variations of solar radiation than is the case at lower levels, the Commission consider it desirable that this new method of investigation be pursued systematically in Europe, America, and elsewhere, in order that the temperature and its variations may be determined in different regions of the globe, and particularly over a wide range of latitude.

\section{Publication of solar daily character figures}

(h) It is recommended that a grant not exceeding forty pounds sterling per annum be made for three years to the Observatoire Fédéral, Zurich, for the publication of the proposed bulletins (item 3 (ii) of this Report) giving for the period January I, I928 to December 3I, I930, daily character figures for various solar phenomena whose correlation with terrestrial phenomena it is desired to examine. 